\title{
RANCANG BANGUN RUMAH PINTAR DENGAN PLATFORM HOME ASSISTANT BERBASIS RASPBERRY PI 3
}

\author{
1) Dany Pratmanto, ${ }^{2)}$ Fandhilah Fandhilah, ${ }^{3)}$ Safuan Adi Saputra \\ ${ }^{1)}$ Sistem Informasi,STMIK Nusa Mandiri Jakarta, ${ }^{2}$ Teknik Informatika, Universitas Bina Sarana \\ ${ }^{1)}$ dany.dto@nusamandiri.ac.id, ${ }^{2)}$ fandhilah.fnd@bsi.ac.id' ${ }^{3)}$ safuanbasa@gmail.com
}

\begin{abstract}
The construction of this Home Automation System uses the concept of the Internet of things as architecture. Home Assistant is a Home Automation platform that is in line with the concept of the Internet of things. By using the Home Assistant framewok, the construction of home automation is easier because there is no need to make server applications and controlling applications. The results of research on the development of Home Automation Systems, namely homeowners can control their home lighting systems, live broadcasts of the state of the house with surveillance cameras, monitoring room temperature, and door locks. All that we can control through the local network and the internet.
\end{abstract}

Keywords - smart home, cloud computing, internet of things (iot), raspberry pi, surveillance cameras

Abstrak - Pembangunan Home Automation System ini menggunakan konsep Internet of things sebagai arsitektur. Home Assistant adalah platform Home Automation yang sesuai dengan konsep Internet of things, dengan menggunakan framewok Home Assistant maka pembangunan home automation menjadi lebih mudah karena tidak perlu membuat aplikasi server dan aplikasi pengendali. Hasil dari penelitian pembangunan Home Automation System, yaitu pemilik rumah dapat mengendalikan sistem pencahayaan rumahnya, siaran langsung keadaan rumah dengan kamera pengintai, pemantauan suhu ruangan, dan pengunci pintu. Semua itu dapat kita kendalikan melalui jaringan lokal maupun internet.

Kata kunci-rumah pintar, cloud computing, internet of things (iot), raspberry pi, kamera pengintai

\section{A. PENDAHULUAN}

Rumah merupakan salah satu tempat untuk menikmati keamanan dan kenyamanan hidup. Namun masyarakat modern sekarang ini sering beraktifitas diluar rumah, sehingga membuat rumah yang ditinggalkan rentan akan tindak kejahatan. Begitu juga dengan penggunaan energi listrik dengan membiarkan peralatan elektronik atau penerangan pada sebuah rumah tetap menyala saat tidak digunakan, mungkin faktor lupa maupun kesibukan yang tinggi pemilik rumah. Perkembangan teknologi saat ini menawarkan kemudahan dalam mengatasi masalah tersebut yang mempermudah pemilik mengamankan rumahnya yaitu dengan melakukan pengawasan dan kendali jarak jauh yang dapat dilakukan melalui gadget.

Untuk mencapai sebuah rumah idaman yang aman dan nyaman, dibutuhkan penerapan suatu teknologi yang dapat membantu hal tersebut seperti sistem kontrol rumah pintar. Rumah pintar ini dapat mengendalikan alat-alat elektronik hanya dengan suatu kendali pusat, dan dapat dikontrol dari jarak jauh. Dengan Raspberry Pi yang menerapkan teknologi nirkabel dan kabel yang dapat memudahkan dalam otomatisasi sebuah rumah. Sehingga diharapkan dapat mengontrol konsumsi listrik dan menghilangkan kekhawatiran akan keamanan rumah.

Penelitian oleh (Arafat, 2016) menerapkan sistem pengaman otomatis pintu yang dapat dipantau dan di kendalikan secara realtime dengan data internet sebagai koneksi jaringannya. Penelitian (Adriansyah, GM, \& Yuliza, 2014) menggunakan Raspberry Pi yang mempermudah penggunaan CCTV online sehingga dapat diaplikasikan di berbagai teknologi lainnya. Kemudian (Prihatmoko, 2017) menggunakan perangkat lampu yang dapat dikontrol dari jarak jauh serta dilengkapi dengan penjadwalan sehingga program energi dapat berjalan dengan baik dan dapat mengurangi pemborosan konsumsi listrik yang digunakan masyarakat. 
Tujuan pembuatan rancang bangun ini adalah memberikan kemudahan bagi pengguna dalam otomatisasi sebuah rumah sehingga dapat menghemat waktu dan finansial sebagai solusi alternatif.

\section{B. TINJAUAN PUSTAKA \\ 1. Raspberry Pi}

Menurut Abdul Kadir (2017:2) menyatakan bahwa Raspberry Pi adalah papan elektronis seukuran kartu kredit yang memiliki fungsi seperti komputer. Jika dihubungkan ke monitor, keyboard, mouse dan jaringan komputer kita dapat menggunakannya laiknya komputer. Kita dapat memakainya untuk menulis dokumen, melayari internet, bermain game, bahkan menjadikannya sebagai web server.

\section{DHT22 Sensor}

Menurut (Saptadi, 2014) mengemukakan bahawa DHT22 adalah sensor seri DHT dari Aosong Electronics yang dapat melakukan pengukuran suhu dan kelembaban secara serempak dengan keluaran digital. Sensor DHT22 memerlukan resistor $10 \mathrm{~K}$ pada pin VCC dan dan pin Data untuk menghindari arus langsung yang masuk ke sensor sebelum masuk ke GPIO Raspberry Pi. Berikut adalah gambar sensor kelembaban dan suhu DHT22.

\section{Raspbian OS}

Raspbian adalah sistem operasi yang direkomendasikan untuk penggunaan normal pada Raspberry Pi. Raspbian adalah sistem operasi bebas berbasis Debian, dioptimalkan untuk perangkat keras Raspberry Pi. Raspbian hadir dengan lebih dari 35.000 paket. Perangkat lunak terkompilasi yang dikemas dalam format yang baik dan pemasangan yang mudah pada Raspberry $\mathrm{Pi}$. Raspbian adalah proyek komunitas dengan dukungan pengembang yang aktif, dengan penekanan pada peningkatan stabilitas dan kinerja paket Debian sebanyak mungkin(The Raspberry Pi Foundation, 2018).

\section{Python}

Python adalah bahasa pemrogramman interpretatif yang dianggap mudah dipelajari serta berfokus dengan keterbacaan kode. Dengan kata lain, Python di klaim sebagai bahasa pemrogramman yang memiliki kodekode pemrogramman yang sangat jelas, lengkap, dan mudah dipahami yang secara umum berbentuk pemrogramman berorientasi objek, pemrogramman imperatif, dan pemrogramman fungsional(Enterprise, 2017:1).

\section{Home Assistant}

Home Assistant adalah home automation platform sumber terbuka yang berjalan di Python 3. Diciptakan pada tahun 2013 oleh
Paulus Schoutsen. Lacak dan kontrol semua perangkat di rumah dengan kendali otomatis. Berjalan sempurna di Raspberry Pi. Lebih dari 950 komponen terkenal telah terintegrasi dengan Internet of Things seperti IKEA Trådfri, Philips Hue, Google Assistant, Alexa/Amazon Echo, Nest, KODI, dsb. Serta dengan dukungan komunitas yang besar, dan lebih dari 830 kontributor(Paulus Schoutsen, 2018).

7. YAML (YAML Ain't Markup Language)

YAML adalah sebuah format standar serialisasi data untuk semua bahasa pemrogramman yang mudah dibaca manusia secara umum(Ben-kiki, Evans, \& Net, 2009).

\section{Motion}

Motion menggunakan perangkat video4linux untuk mendeteksi gerakan. Jika gerakan terdeteksi baik gambar normal dan gerak akan diambil. Motion juga dapat mengambil tindakan dan mengirimkan laporan jika diperlukan. Pembuatan snapshot otomatis juga dimungkinkan(Vreeken, Heusden, \& Lavrsen, 2018).

\section{Shell Program}

shell adalah program yang menerima perintah dari keyboard lalu mengirimkannya ke sistem operasi untuk dieksekusi. Di masa lalu, shell adalah satu-satunya program yang tersedia pada sistem operasi mirip Unix seperti Linux (CLI). Tapi sekarang memiliki antarmuka pengguna grafis (GUI) seperti Terminal Linux yang memungkinkan pengguna berinteraksi dengan shell (William E. Shotts, 2018).

\section{Leafpad}

Leafpad adalah penyunting teks GTK+ ringan yang menekankan kesederhanaan. Karena pengembangan berfokus pada menjaga bobot seminimal mungkin, hanya fitur yang paling penting yang diimplementasikan dalam penyunting. Leafpad mudah digunakan, mudah dikompilasi, membutuhkan sedikit pustaka, dan dapat dijalankan dengan cepat (tarot at freeshell organization, 2018)

\section{METODE PENELITIAN}

\section{Observasi}

Metode ini dilakukan dengan proses pengamatan langsung yang berhubungan dengan proses pembuatan alat kendali lampu dan keamanan kamera web.

\section{Studi Pustaka}

Penulis mempelajari buku-buku referensi, jurnal-jurnal di internet dan literatur-literatur lain yang berhubungan dengan pembuatan laporan ini.

\section{PERANCANGAN SISTEM}

Proyek rumah pintar ini berbasiskan komputer mini Raspberry Pi yang menjalankan sistem 
operasi Debian, lebih tepatnya Distro Raspbian. Sistem operasi ini sangat stabil dan menggunakan sumber daya yang rendah sehingga sangat cocok digunakan untuk mini komputer. Serta didukung dengan pemrogramman Python yang saat ini sudah mencapai versi 3 . Proyek ini menyediakan empat fungsi penting untuk sistem rumah, yakni mengendalikan peralatan rumah seperti lampu, pemantauan suhu dan kelembaban, kunci pintu dengan solenoid dan kamera pengintai dengan biaya murah. Ponsel pintar digunakan sebagai perangkat pengendali melalui peramban web dimana alamat IP server sudah di pintaskan di home screen. Router adalah persyaratan untuk membangun sistem ini karena sebagai penghubung antara Raspberry $\mathrm{Pi}$ dan perangkat pengendali. Selain itu, kode pemrograman sendiri melibatkan beberapa jenis bahasa seperti Python, program shell, YAML sebagai konfigurasi. Framework Home Assistant digunakan untuk antarmuka penyedia layanan web dan program Motion yang nantinya kita gunakan untuk mengolah sinyal video dari kamera USB.

\section{Blok Diagram}

Blok diagram Rancang Bangun Rumah Pintar Dengan Platform Home Assistant berbasis Raspberry Pi 3 yang dibuat adalah sebagai berikut:

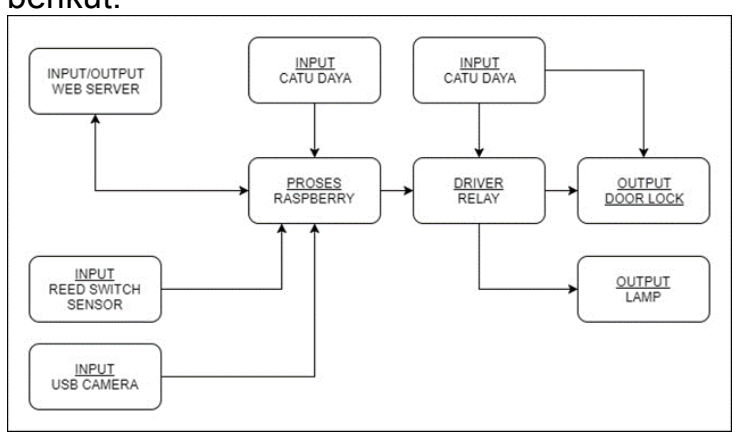

\section{Gambar Blok Diagram Alat}

\section{Skema Rangkaian}

Skema rancang bangun yang dibuat adalah sebagai berikut:
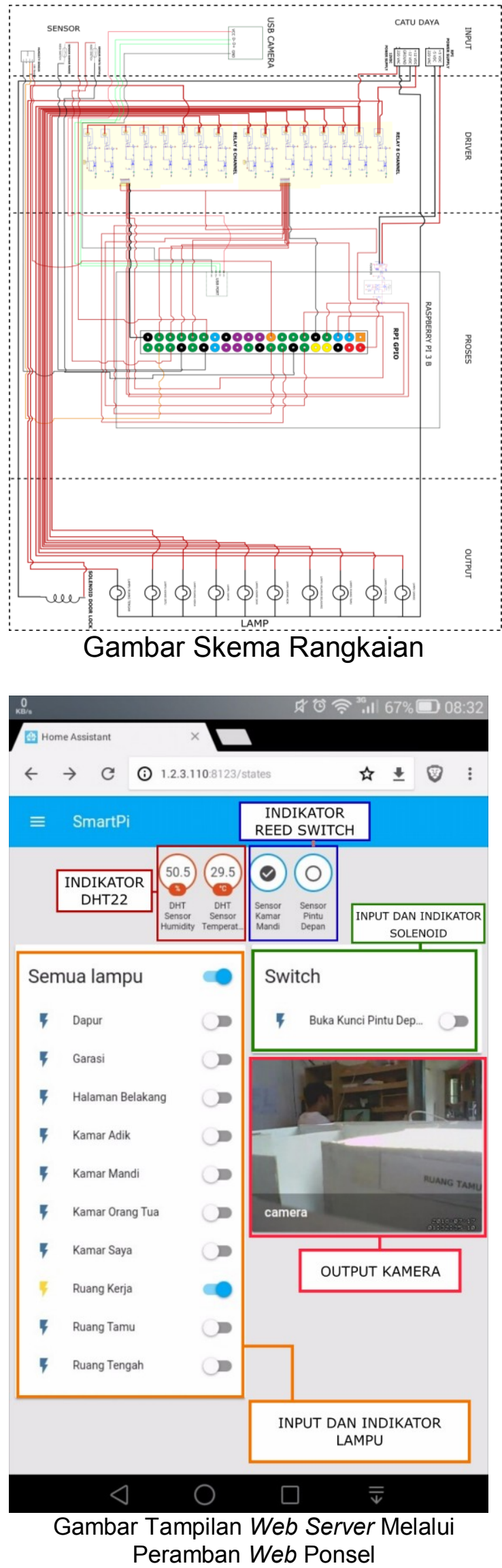


\section{E. HASIL DAN PEMBAHASAN}

Raspberry Pi membutuhkan catu daya 5 volt 2,5 ampere DC agar semua periperal yang terhubung dapat bekerja dengan baik. Kurangnya tengangan mengakibatkan Raspberry $\mathrm{Pi}$ tidak dapat booting dan kelebihan catu daya dapat merusak Raspberry Pi.

\section{Pengujian Komponen}

a. Kamera WEB

Langkah ini adalah menguji apakah kamera sudah bisa diakses secara daring melalui jaringan lokal atau localhost, yaitu dengan mengetik alamat IP dan port Motion dari Raspberry Pi pada peramban web.

Tabel Kebutuhan bandwitdh siaran langsung.

\begin{tabular}{|c|c|c|}
\hline No. & Bandwitdh & Status \\
\hline 1 & $<40 \mathrm{~KB} / \mathrm{s}$ & jeda 1 detik atau lebih \\
\hline 2 & $<85-40 \mathrm{~KB} / \mathrm{s}$ & Jeda 0.5 detik \\
\hline 3 & $\geq 85 \mathrm{~KB} / \mathrm{s}$ & lancar \\
\hline
\end{tabular}

\section{b. DHT22 Sensor}

Pengujian ini dilakukan selama 1 hari dengan pengambilan data suhu dan kelembaban pada waktu pagi, siang, sore dan malam.

Tabel Hasil uji coba sensor suhu dan kelembaban $D H T 22$

\begin{tabular}{|c|c|c|c|}
\hline NO & \multicolumn{2}{|c|}{ Waktu } & $\begin{array}{c}\text { Output DHT22 } \\
\text { Temperatur/Kelemba } \\
\text { ban }\end{array}$ \\
\hline 2 & Pagi & $6: 00$ WIB & $29,5^{\circ} \mathrm{C} / 58,6 \%$ \\
\hline 3 & Siang & $12: 00$ WIB & $32,4^{\circ} \mathrm{C} / 55,1 \%$ \\
\hline 4 & Sore & $16: 00$ WIB & $33,3^{\circ} \mathrm{C} / 54 \%$ \\
\hline 5 & Malam & $21: 00$ WIB & $31,6^{\circ} \mathrm{C} / 61 \%$ \\
\hline
\end{tabular}

c. Reed Switch Sensor

Tabel Hasil Uji Coba Reed Switch Sensor Pintu Depan

\begin{tabular}{|l|l|l|}
\hline Pintu & ID Magnet & Indikator $\mathbf{W e b}$ \\
\hline Tertutup & Terpasang & On \\
\hline Terbuka & Terpasang & Off \\
\hline
\end{tabular}

\section{d. Solenoid Door Lock}

Pengujian pada solenoid melalui pengukuran tegangan menggunakan multimeter digital. Pengukuran dilakukan dengan cara menghubungkan konektor positif multimeter pada solenoid penghubung positif dan konektor negatif pada ground.

Tabel Hasil Pengukuran Tegangan Pada Solenoid

\begin{tabular}{|c|c|c|}
\hline Kondisi & $\begin{array}{c}\text { Tegangan } \\
\text { tertinggi }\end{array}$ & $\begin{array}{c}\text { Tegangan } \\
\text { terendah }\end{array}$ \\
\hline Tidak aktif & 0.00 volt & 0.00 volt \\
\hline Aktif & 11.65 volt & 11.64 volt \\
\hline
\end{tabular}

\section{Pengujian Keseluruhan}

a. Kunci Pintu

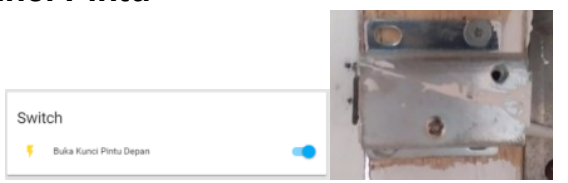

Gambar Tombol Toggle Buka Kunci Pintu Depan On dan Pengunci Tertarik.

\section{b.Sensor Pintu}

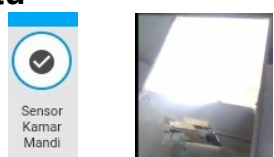

Gambar Ikon Indikator Sensor Sedang On dan Lampu Kamar Mandi Menyala

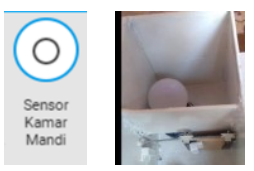

Gambar Pintu Kamar Mandi Terbuka dan Lampu Padam

\section{c. Sensor Pintu Depan}

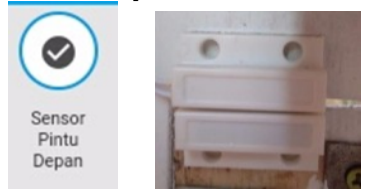

Gambar Pintu Tertutup dan Ikon Indikator Sensor Sedang On

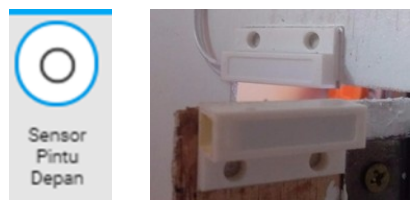

Gambar Reed Switch dan Magnet Terpisah dan indikator sensor Off

d. Lampu

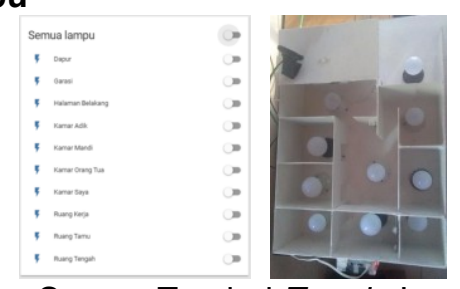

Gambar Semua Tombol Toggle Lampu Off dan Semua Lampu padam

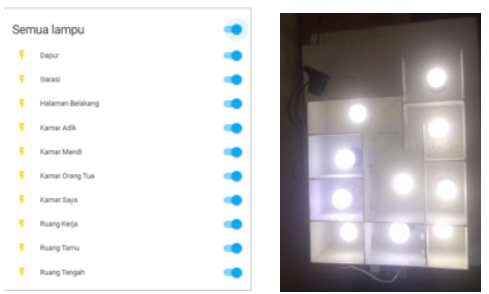

Gambar Semua Tombol Toggle Lampu On dan Semua Lampu Menyala 
e. Kamera WEB
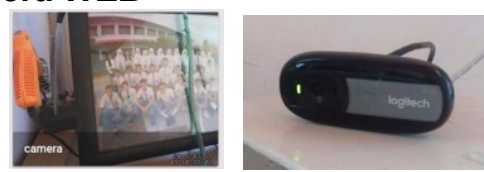

Gambar Indikator Kamera USB Menyala dan Menayangkan Siaran Langsung

\section{f. Sensor DHT22}

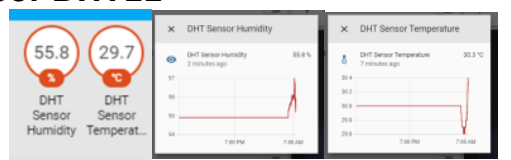

Gambar Indikator Keluaran Sensor DHT22 dan tampilan grafik keluaran

\section{F. KESIMPULAN}

Sistem rumah pintar dapat mengendalikan peralatan rumah seperti lampu, pemantauan suhu dan kelembaban, kunci pintu dengan solenoid dan kamera pengintar. Ponsel pintar digunakan sebagai perangkat pengendali melalui peramban web dimana alamat IP server sudah di pintaskan di home screen. Router adalah persyaratan untuk membangun sistem ini karena sebagai penghubung antara Raspberry $\mathrm{Pi}$ dan perangkat pengendali. Framework Home Assistant digunakan untuk antarmuka penyedia layanan web dan program Motion yang nantinya kita gunakan untuk mengolah sinyal video dari kamera USB.

\section{DAFTAR PUSTAKA}

Abdul Kadir. (2017). Dasar Raspberry Pi. (Seno, Ed.). Yogyakarta: CV. ANDI OFFSET.

Arafat. (2016). SISTEM PENGAMANAN PINTU RUMAH BERBASIS Internet Of Things ( loT ) Dengan ESP8266. Jurnal IImiah Fakultas Teknik "Technologia," 7(4), 262-268. Retrieved from https://ojs.uniska-

bjm.ac.id/index.php/JIT/article/view/661

Adriansyah, A., GM, M. R., \& Yuliza. (2014). Rancang Bangun Dan Analisa Cctv Online Berbasis Raspberry Pi, 105-110. Retrieved from https://www.researchgate.net/publication /315781688_RANCANGBANGUN_DAN _ANALISA_CCTV_ONLINE_BERBASIS _RASPBERRY_PI

Ben-kiki, O., Evans, C., \& Net, I. döt. (2009). YAML Ain 't Markup Language ( YAML TM ) Edition , Patched at 2009-10-01. Retrieved from http://yaml.org/spec/1.2/spec.pdf

Enterprise, J. (2017). Otodidak Pemrogramman Python. Jakarta: PT Elex Media Computindo. Retrieved from https://books.google.co.id/books?id=KM8DwAAQBAJ\&dq=ebook+belajar+pyth on\&hl=id\&source=gbs_navlinks_s

Paulus Schoutsen. (2018). Home Assistant. Retrieved July 8, 2018, from https://www.home-assistant.io/

Saptadi, A. H. (2014). Perbandingan Akurasi Pengukuran Suhu dan Kelembaban Antara Sensor DHT11 dan DHT22. Jurnal Infotel No. 2, 6, 49-56. Retrieved from

http://ejournal.st3telkom.ac.id/index.php/i nfotel/article/view/16

tarot at freeshell organization. (2018). Leafpad. Retrieved from http://tarot.freeshell.org/leafpad/

The Raspberry Pi Foundation. (2018). Raspberry Pi. Retrieved July 8, 2018, from https://www.raspberrypi.org

Vreeken, J., Heusden, F. van, \& Lavrsen, K. (2018). motion(1) - Linux man page. Retrieved October 8, 2018, from https://linux.die.net/man/1/motion

William E. Shotts, J. (2018). Learning The Shell. Retrieved July 19, 2018, from http://linuxcommand.org/lc3_Its0010.php 